\title{
Urgensi Pendidikan Kristen Berdasarkan Alkitab
}

\section{Yosia Belo}

Sekolah Tinggi Teologi Injili Arastamar (SETIA) Jakarta

ociebelo42@gmail.com

\begin{abstract}
This study was conducted to determine the urgency of Bible-based Christian education. By using qualitative research methods, researchers find the urgency of Biblebased Christian Education so that Christian Education becomes a means for every student to understand salvation in Christ and know Him and even live out that salvation in their practical life. In addition, so that Christian Education can make students aware of their sinful lives; can change the character of each student so that it is always in harmony with the Bible and always guides students to walk in God's will.
\end{abstract}

Keywords: Christian Education, Bible, Urgency

Abstrak: Penelitian ini dilakukan untuk mengetahui urgensi pendidikan Kristen berdasarkan Alkitab. Dengan menggunakan metode penelitian kualitatif, peneliti menemukan urgensi Pendidikan Kristen berdasarkan Alkitab supaya Pendidikan Kristen menjadi sarana bagi setiap peserta didik untuk mengerti keselamatan di dalam Kristus dan mengenal-Nya bahkan menghidupi keselamatan itu dalam kehidupan praktisnya. Selain itu, supaya Pendidikan Kristen dapat menyadarkan peserta didik dari kehidupannya yang berdosa; dapat mengubah karakter setiap peserta didik agar senantiasa selaras dengan Alkitab serta senantiasa menuntun peserta didik untuk berjalan dalam kehendak Allah.

Kata Kunci: Pendidikan Kristen, Alkitab, Urgensi

\section{Pendahuluan}

Setiap apa yang dilakukan tentunya mempunyai tujuan. Karena tidak ada sebuah perbuatan yang dilakukan oleh setiap individu tanpa adanya tujuan atau goal yang hendak dicapai. Bahkan tindakan kejahatan sekalipun dilakukan untuk sebuah tujuan. Demikian halnya pendidikan yang dilakukan atau di mana hampir setiap individu terlibat di dalamnya juga memiliki tujuan.

Secara umum, pendidikan bertujuan untuk mencerdaskan dan untuk membagikan pengetahuan kepada setiap individu. Pada Undang-undang Nomor 20 tahun 2003 tentang Sistem Pendidikan Nasional, Pasal 3, tujuan pendidikan nasional adalah mengembangkan potensi peserta didik agar menjadi manusia yang beriman dan bertakwa kepada Tuhan Yang Maha Esa, berakhlak mulia, sehat, berilmu, cakap, kreatif, mandiri, dan menjadi warga negara yang demokratis serta bertanggung jawab.

Dengan demikian, dapat dikatakan bahwa setiap pengetahuan yang ditransfer kepada setiap peserta didik, tidak hanya menjadikannya sebagai individu yang berilmu. 
Akan tetapi juga dapat menjadikannya sebagai individu yang yang berakhlak mulia, bertaqwa kepada Tuhan, hingga menjadikannya individu yang cakap, kreatif, mandiri dan bertanggung jawab.

Lalu bagaimana dengan pendidikan Kristen? Apa yang menjadi tujuan dari pendidikan Kristen? Dan bagaimana cara untuk mencapai setiap tujuan yang dimaksud? Pendidikan Kristen ${ }^{1}$ dilaksanakan pastinya memiliki tujuan yang jelas. Tujuan Pendidikan Kristen dari masa ke masa mengalami perkembangan, khususnya dalam rumusan tujuan Pendidikan Kristen. Ada banyak formula atau rumusan tujuan pendidikan Kristen yang dikemukakan pendidik Kristen.

Martin Luther memang tidak memakai istilah tujuan pendidikan Kristen karena istilah ini dipakai secara teratur setelah pokok pendidikan itu dijadikan sebagai ilmu tersendiri. Akan tetapi, dari apabila membaca karya Luther terhadap pendidikan, maka dapat dirumuskan tujuan pendidikan Kristen menurut Marhin Luther yaitu untuk menyadarkan anak didik dan orang dewasa tentang keadaan mereka yang sebenarnya, yaitu mereka orang berdosa. Maka setiap warga harus bertobat dan berseru kepada Allah agar diampuni. Dengan kata lain, tujuan pendidikan Kristen menurut Marhin Luther yaitu melibatkan semua warga jemaat, khususnya yang muda dalam rangka belajar teratur dan tertib agar semakin sadar akan dosa mereka serta bergembira dalam Firman Yesus Kristus yang memerdekakan mereka di samping memperlengkapi mereka dengan sumber iman, khususnya pengalaman berdoa, Firman tertulis, Alkitab, dan rupa-rupa kebudayaan sehingga mereka mampu melayani sesamanya termasuk masyarakat dan negara serta mengambil bagian secara bertanggungjawab dalam persekutuan kristen yaitu Gereja. ${ }^{2}$

Berdasarkan tujuan pendidikan Kristen di atas maka disusunlah kurikulum yang tentunya untuk dirumuskan guna mencapainya. Dan apabila memperhatikan tujuan yang dirumuskan maka hanya berdasarkan Alkitablah maka tujuan pendidikan Kristen seperti di atas dapat tercapai.

\section{Metode Penelitian}

Pada penelitian ini, penulis atau peneliti menggunakan pendekatan atau metode kualitatif untuk memperoleh data yang valid guna membangun sebuah teori yang berkaitan dengan tema atau pokok penelitian. Metode kualitatif yang dimaksud adalah mengkaji dan mengelaborasi setiap sumber, informasi dan data-data yang diperoleh dari pustaka.

\footnotetext{
${ }^{1}$ Mavis L. Anderson, memberikan definisi mendidik dalam hubungannya dengan mengajar dengan mengkaitkannya dengan Pendidikan Kristen, dengan berkata: "Kata mendidik berarti "memimpin atau membimbing pembentukan kebiasaan-kebiasaan yang menuju kepada kecakapan", pada jalan yang harus ditempuhnya, mempunyai arti yang lebih luas daripada hanya memberikan pengetahuan teori sebanyakbanyaknya ke dalam hati murid-murid yang belum bersedia dengan satu pengharapan bahwa kelak pada akhir perjalanan yang jauh ini, murid akan tiba pada tujuan yang benar. Hal ini berarti membimbing dan melatih kehidupan itu dibawah pemeliharaan Roh Allah, sehingga langkah demi langkah, ia dipimpin kepada saat dimana ia menerima Dia yang adalah "jalan dan kebenaran dan Hidup" (Yoh. 14:6)" (Mavis L. Anderson, Pola mengajar Sekolah Minggu, Yayasan kalam hidup, Bandung, 1993, hlm. 90).

${ }^{2}$ Robert R. Boehlke, Sejarah Perkembangan Pikiran dan Praktek PAK, (Jakarta: BPK Gunung Mulia, 2002), hlm. 340 .
} 


\section{Hasil dan Pembahasan \\ Definisi Pendidikan Kristen}

E.G. Homrighausen mengatakan, "Pendidikan Agama Kristen berpangkal pada persekutuan umat Tuhan. Dalam Perjanjian Lama pada hakikatnya dasar-dasar terdapat pada sejarah suci purbakala, bahwa Pendidikan Agama Kristen itu mulai sejak terpanggilnya Abraham menjadi nenek moyang umat pilihan Tuhan, bahkan bertumpu pada Allah sendiri karena Allah menjadikan umat-Nya sebagai peserta didik". ${ }^{3}$

Menurut Warner C. Graedorf, Pendidikan Kristen adalah "Proses pengajaran dan pembelajaran yang berdasarkan Alkitab, berpusat pada Kristus, dan bergantung kepada Roh Kudus, yang membimbing setiap pribadi pada semua tingkat pertumbuhan melalui pengajaran masa kini ke arah pengenalan dan pengalaman rencana dan kehendak Allah melalui Kristus dalam setiap aspek kehidupan, dan melengkapi mereka bagi pelayanan yang efektif, yang berpusat pada Kristus sang Guru Agung dan perintah yang mendewasakan pada murid". 4

Bahkan John Calvin seperti yang dikutip dari buku Paulus Lilik Kristanto mengatakan, "PAK adalah pendidikan yang bertujuan mendidik semua putra-putri gereja agar mereka: (1) Terlibat dalam penelaahan Alkitab secara cerdas sebagaimana dengan bimbingan Roh kudus, (2) Mengambil bagian dalam kebaktian dan memahami keesaan gereja, dan (3) diperlengkapi untuk memilih cara-cara mengejawantahkan pengabdian diri kepada Allah Bapa dan Yesus Kristus dalam pekerjaan sehari-hari serta hidup bertanggung jawab di bawah kedaulatan Allah dan kemuliaanNya sebagai lambang ucapan syukur mereka yang dipilih dalam Yesus Kristus". ${ }^{5}$

Apabila memperhatikan beberapa definisi yang para ahli kemukakan tentang Pendidikan (Agama) Kristen, maka dapat disimpulkan bahwa Pendidikan Kristen seyogyanya harus didasarkan pada Alkitab. Karena justru pengajaran Alkitab itulah yang kemudian memberikan warna tersendiri bahkan substansi terhadap pendidikan Kristen.

\section{A. Pendidikan Kristen Dalam Alkitab}

Pendidikan Agama Kristen harus didasarkan kepada Alkitab. Oleh karena tanpa Alkitab, Pendidikan Agama Kristen akan hambar dan tidak memiliki kuasa. Pendidikan Kristen berawal pada persekutuan umat Tuhan dalam Perjanjian Lama. Di mana bangsa Yahudi yang adalah bangsa kecil tetapi dipilih dan diberikan kekuatan serta kelimpahan oleh Tuhan sehingga menjadi bangsa yang besar dan menikmati persekutuan dengan Tuhan.

Mereka selalu menonjol dan memberi pengaruh kuat kepada dunia. Mereka adalah bangsa yang memiliki identitas yang kuat. Hal yang paling mengesankan dalam budaya Yahudi adalah perhatian mereka terhadap pendidikan. Pendidikan menjadi bagian utama dan terpenting dalam budaya Yahudi. Objek utama dalam pendidikan

\footnotetext{
${ }^{3}$ E.G.Homrighausen, Pendidikan Agama Kristen, (Jakarta: BPK Gunung Mulia, 1985), Hal. 112

${ }^{4}$ Paulus Lilik Kristanto, Prinsip dan Praktek PAK Penuntun bagi Mahasiswa Teologi dan PAK, Pelayan Gereja, Guru Agama dan keluarga Kristen, (Yogyakarta : Andi Offset ), Hal. 4

${ }^{5}$ Ibid.
} 
ialah mempelajari Taurat. Allah menggunakan Taurat sebagai media pengajaran-Nya; pertama-tama Allah memperkenalkan diri-Nya, menyatakan pekerjaan yang telah Dia lakukan, kemudian mengarahkan pengajaran-Nya kepada hubungan Allah (pribadiNya) dengan manusia (umat-Nya), serta manusia dengan manusia selaku umat yang telah dipilih dan diselamatkan. Hampir seluruh kitab Perjanjian Lama menjelaskan secara khusus perihal komponen pembelajaran antara lain pendidik, yaitu parapemimpin Israel yang turut berperan dalam pendidikan. Peserta didik yaitu umat Israel yang menerima pendidikan. Kurikulum yaitu materi atau isi pendidikan yang mencakup ketetapan dan peraturan (Ul. 6:1) atau Taurat Tuhan. Sedangkan komponen pembelajaran yang lain adalah tujuan dan metode.

Tujuan pendidikan bagi umat Israel adalah mewujudkan visi Allah bagi bangsabangsa. Visi Allah merupakan dasar pendidikan yang perlu dijalankan dari rumah orang Ibrani dalam rangka menyelamatkan bangsa-bangsa didunia melalui keteladan hidup orang Ibrani (Kej. 12). Tujuan utama pengajaran masa kini adalah menyelamatkan anak didik terlebih dulu (percaya kepada Yesus) melalui firman Allah yang mencerminkan kehidupan rohani dalam nilai-nilai kristiani. Selain itu tujuan pembelajaran adalah agar para peserta didik menjadi saluran berkat bagi orang lain dalam memberitakan kabar baik agar orang lain juga diselamatkan. Metode dan pendekatan dalam Perjanjian Lama dilakukan melalui penglihatan (penampakan Allah), pengajaran para imam dalam rumah-rumah ibadah, atau pengajaran para raja di istana dan sejumlah rumah ibadat (sinagoge).

Tema pokok pengajaran dalan PL dan PB adalah sama-sama mengenai karya penyelamatan Allah bagi manusia. Dalam PB hal ini dinyatakan pada pribadi Yesus Kristus sebagai Juruselamat. Tuhan Yesus Kristus layak disebut Guru Agung karena pengajaran-Nya disertai kuasa mukjizat. Sehubungan dengan itu, ada tujuh hal utama yang menjelaskan arti penting mengajar, yaitu: (1) Menjelaskan firman yang sudah diwahyukan (2 Tim 2:14; 3:16-17); (2) Menguatkan iman (1 Tim 4:6, 11, 16; 6:3-5); (3) Membentuk keharmonisan rumah tangga (1 Tim 6:1-2); (4) Merupakan syarat mutlak bagi pendeta dan pemimpin rohani (1 Tim 3:2; 2 Tim 2:24); (5) Mendorong seseorang untuk membaca, menghayati, dan memberitakan firman Tuhan (1 Tim 4:13; 2 Tim 4:2); (6) Menjelaskan pertumbuhan iman (2 Tim 2:2); dan (7) Memuridkan ( Mat 28:19-20, 2 Tim 2:2).

Bahkan dalam kitab Injil juga seringkali dijumpai bahwa salah satu aktivitas yang rutin dan secara terstruktur dilakukan oleh Yesus adalah mengajar. Dalam Bahasa

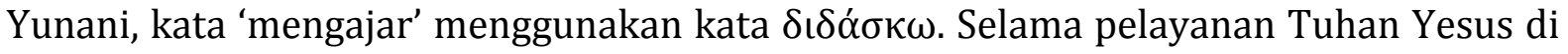
Galilea dalam catatan keempat Injil kanonik, kata $\delta$ เ $\delta$ ó $\sigma \omega \omega$ muncul sebanyak 27 kali dalam beragam modus dan tense. Dalam Injil Matius, selama pelayanan Tuhan Yesus di Galilea; penulis Injil menggunakan kata ini sebanyak 8 kali untuk menunjuk kepada aktivitas mengajar Tuhan Yesus. Misalnya dalam Matius 4:23 ketika dijelaskan tentang pekerjaan Tuhan Yesus yang berkeliling seluruh wilayah Galilea untuk mengajar dan

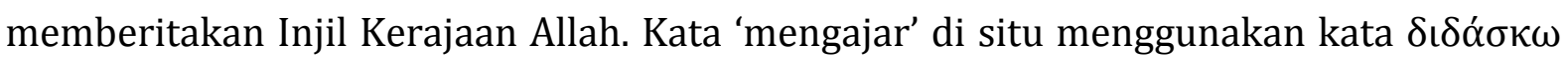
dalam modus partisip, yakni: $\delta \iota \delta \alpha ́ \sigma \kappa \omega \nu$. Kemudian kata tersebut juga muncul dalam

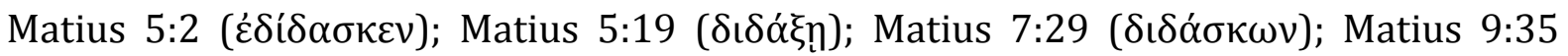




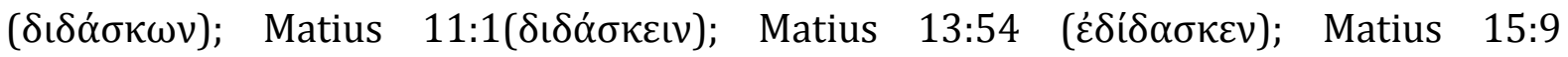
$(\delta \mathrm{\iota} \delta \alpha ́ \sigma \kappa o v \tau \varepsilon \varsigma){ }^{6}$

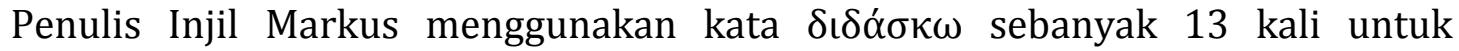
menjelaskan aktivitas mengajar Tuhan Yesus selama di Galilea. Misalnya dalam Markus

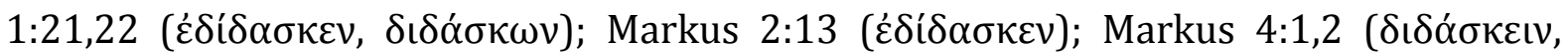

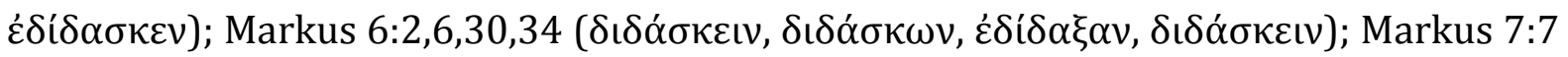

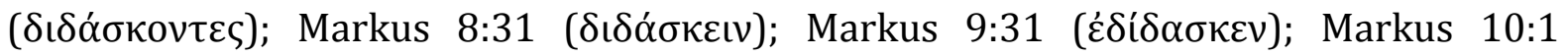
( $\dot{\delta} \delta \dot{\delta} \delta \alpha \kappa \varepsilon \nu)$.

Dalam Injil Lukas kata ini hanya muncul 5 kali selama mengisahkan tentang pelayanan Tuhan Yesus di wilayah Galilea. Misalnya dalam Lukas 4:15, 31 ( $\varepsilon \dot{\delta} \delta \alpha \sigma \kappa \varepsilon v$,

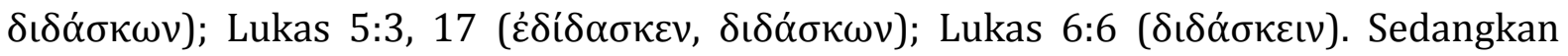
dalam Injil Yohanes kata ini muncul hanya muncul 1 kali selama pelayanan Tuhan Yesus

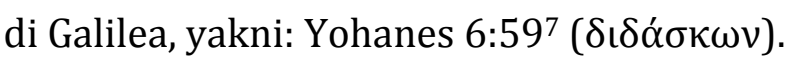

Kata $\delta เ \delta \alpha ́ \sigma \kappa \omega$ sendiri dapat diartikan "to teach, Matthew $4: 23 ; 22: 16$, and on others texts; to teach or speak in public assembly, 1 Timothy 2:12; to direct, admonish, Matthew 28:15; Romans 2:21, and on others texts" (Perschbacher 1990, 98). Berdasarkan informasi di atas, maka kata ini dapat diartikan atau pun dipahami dengan mengajar apabila dilihat konteksnya dalam Matius 4:23; 22:16 dan pada teks-teks yang lain. Apabila memperhatikan penggunaannya dalam 1 Timotius 2:12 maka dapat diartikan dengan mengajar atau berbicara di depan pertemuan/publik. Matius 28:15; Roma 2:21 dan pada teks-teks yang lain, kata ini dipahami dengan mengarahkan dan menegur. Arti yang tidak jauh berbeda diberikan atau dikemukakan oleh Bauer. Baginya, kata $\delta ı \delta \alpha \sigma \kappa \omega$ dapat dipahami atau diartikan: (1) untuk memberitahukan seseorang apa yang harus dilakukan, katakan, menginstruksikan, misalnya yang terdapat dalam Matius 28:15; (2) untuk memberikan instruksi dalam suasana formal dan informal, mengajar - seperti dalam Matius 4:23; Mrk. 1:21; Yoh. 7:14; 1 Kor. 4:17; 1 Tim.4:11; 6:2; dll (BDAG 2000, 241). Kata ini dapat dipahami sebagai sebuah tindakan memberitahukan seseorang apa yang harus dilakukan bisa dalam bentuk formal maupun informal, melalui perkataan yang bersifat instruksional atau pun pengajaran.

Apa yang diajarkan? Yang diajarkan adalah Injil Kerajaan Allah. Menurut Adi Putra dalam bukunya, pokok Kerajaan Surga atau Allah dalam Perjanjian Baru khususnya dalam Kitab-kitab Injil, semuanya berkaitan dengan penggenapan atau pemenuhan. Pemenuhan janji dalam Perjanjian Lama melalui dan oleh Tuhan Yesus

${ }^{6}$ Adi Putra, Misi Yesus Kepada Bangsa-bangsa Lain: Kajian Biblika terhadap Pelayanan Yesus di Galilea Berdasarkan Matius 4:12-17, (Jakarta: Penerbit Vieka Wahana Semesta, 2015), hlm. 58-60.

${ }^{7}$ Menurut Carson, Yesus sedang mengajar di sebuah Sinagoge di Kapernaum. Apa yang diajarkan oleh Tuhan Yesus adalah kembali merujuk kepada ayat 27-58. Itu berarti Dia sedang mengajarkan tentang topik yang ada dalam Keluaran 16 dan Yesaya 54, yakni tentang manna dan pengajaran langsung dari Allah (Carson 1991, 299-300). Informasi diperoleh dari J. Ramsey Michaels, dalam Codex D menambahkan "on the Sabbath" (lihat ay.44). Hal ini hendak menegaskan bahwa Tuhan Yesus pada waktu itu sedang mengajar di Sinagoge di Kapernaum pada hari Sabat (bdk. Mrk. 1:21; Luk.4:31), (Michaels 2010, 403). Artinya, apa yang Tuhan Yesus ajarkan dalam konteks ini adalah tentang manna yang terdapat dalam Perjanjian Lama (khususnya Kitab Musa) serta tentang nubuat nabi Yesaya tentang suatu waktu Tuhan akan mengajar langsung umat-Nya. Meskipun banyak diskusi tentang tempat dan siapa pendengar pengajaran Tuhan Yesus, akan tetapi dengan memperhatikan konten dari pengajaran-Nya maka besar kemungkinan itu terjadi dalam Sinagoge dan didengarkan atau disaksikan oleh orang-orang Yahudi-Galilea. 
Kristus. Dan juga telah disampaikan dalam bab sebelumnya, bahwa untuk dapat memahami kerajaan Allah yang sudah dekat maka diperlukan sebuah pengertian yang benar terhadap setiap pengajaran Tuhan Yesus, khususnya dalam perumpamaan seperti dalam Markus 4:26-29 di mana Kerajaan Allah diumpamakan benih yang terus bertumbuh dari sejak berita itu disampaikan (melalui atau oleh Tuhan Yesus) hingga kepada akhir zaman. Melalui tindakan atau pelayanan Tuhan Yesus yang menyembuhkan serta mengusir kuasa Setan, mengajar, dan memberitakan Injil; menjadi suatu pertanda bahwa Kerajaan Allah sudah ada di bumi. ${ }^{8}$ Meskipun semuanya itu nanti akan mencapai kesempurnaan pada waktu kedatangan-Nya yang kedua. ${ }^{9}$

\section{B. Urgensi Pendidikan Kristen Berdasarkan Alkitab}

Apabila berbicara urgensi PAK berdasarkan Alkitab, maka dalam penelitian ini akan difokuskan kepada teks dalam 2 Timotius 3:16, yang dapat dirinci ke dalam beberapa point berikut ini:

\section{Karena Alkitab memang bermanfaat untuk mengajar}

Kata dasar dari kata "mengajar" adalah kata "ajar." Di dalam Kamus Besar Bahasa Indonesia dijelaskan yang dimaksud dengan kata "ajar" adalah petunjuk yang diberikan kepada orang supaya diketahui (diturut). Sedangkan yang dimaksud dengan kata "mengajar" ialah memberi pelajaran, melatih. Kata benda Yunani yang dipakai ialah didaskalia "didaskalia." Kata benda tersebut berjenis akusatif feminim tunggal. Kata ini berasal dari kata $\delta ı \delta \alpha ́ \sigma \kappa \omega$ yang artinya mengajar atau peringatan. ${ }^{10}$ Kata ini muncul dua puluh satu kali dalam Perjanjian Baru yaitu : ajaran 10 kali, ajaran-ajaran 1 kali, ajaranku 1 kali, ajaranmu 1 kali, mengajar 4 kali, menurut ajaran 1 kali, pelajaran 1 kali, pengajaran 1 kali, pengajaranmu 1 kali.

Mengajar yang dimaksud dalam 2 Timotius 3:16 ialah mengajar tentang keselamatan yang dari Kristus. Dalam Perjanjian Baru dijelaskan gambaran tentang Yesus, tentang apa yang telah terjadi dalam hidup-Nya dan hal-hal yang telah diajarkanNya. Contoh ayat Alkitab dalam Perjanjian Baru yang menjelaskan bagaimana Kristus mengajar yaitu dalam Matius 4:23 "Yesuspun berkeliling di seluruh Galilea; Ia mengajar dalam rumah-rumah ibadat dan memberitakan Injil Kerajaan Allah serta melenyapkan

\footnotetext{
${ }^{8}$ Barnett juga memberikan beberapa argumentasi perihal tanda-tanda kehadiran Kerajaan Allah di bumi. Menurutnya, kosmik dan karakter apokaliptik dari syarat yang signifikan moment Allah yang kuat didemonstrasikan. Utusan diperhadapkan dengan roh-roh jahat, dan dengan kuasa Allah mereka diusir dari kehidupan manusia (Mrk. 1:23-28 [bdk. 3:11]; 5:1-13; 7:24-30; 9:14-19). Seperti Yesus pergi ke Galilea, 'orang kuat' telah diikat dan tawanan itu dibebaskan (Mrk. 3:27). Sudah pasti, Yesus juga telah menyembuhkan penyakit, tetapi Dia melakukannya karena kasihan, respons pada mereka yang menangis minta tolong. Proklamasi Yesus tentang kerajaan dan pengusiran roh-roh jahat itu berbeda. Memproklamirkan dan mengusir lebih aktif, merupakan sebuah misi 'mencari dan menghancurkan' untuk membebaskan tawanan-tawanan dari penjara (sel bawah tanah) Iblis. Yesus menggabungkan tanda-tanda dari Kerajaan Allah ini dengan panggilan pemberita untuk 'bertobat', panggilan kenabian untuk Israel 'kembali' kepada Yahwe, Allahnya (Barnett 1999, 158).

9 Adi Putra, Misi Yesus Kepada Bangsa-bangsa Lain: Kajian Biblika terhadap Pelayanan Yesus di Galilea Berdasarkan Matius 4:12-17, (Jakarta: Penerbit Vieka Wahana Semesta, 2015), hlm. 170-71

${ }^{10}$ Haroul K. Moulton, Leksikon Analitis Bahasa Yunani Yang Direvisi, Pen. Robert Leland dan Stanley Pouw, (Jogjakarta : Randa’s Family Press, 2009), hlm. 90.
} 
segala penyakit dan kelemahan di antara bangsa itu." Juga dalam Matius 7:29 "sebab Ia mengajar mereka sebagai orang yang berkuasa, tidak seperti ahli-ahli Taurat mereka."

Dalam Perjanjian Lama, Allah sendiri berbicara kepada Musa supaya mereka mengajarkan firman Tuhan kepada anak-anak mereka "Apa yang kuperintahkan kepadamu pada hari ini haruslah engkau perhatikan,haruslah engkau mengajarkannya berulang-ulang kepada anak-anakmu dan membicarakannya apabila engkau duduk di rumahmu, apabila engkau sedang dalam perjalanan, apabila engkau berbaring dan apabila engkau bangun. Haruslah juga engkau mengikatkannya sebagai tanda pada tanganmu dan haruslah itu menjadi lambang di dahimu, dan haruslah engkau menuliskannya pada tiang pintu rumahmu dan pada pintu gerbangmu." (Ul. 6:6-9).

Umat Israel diperintahkan untuk mengajarkan firman Allah dengan rajin kepada anak-anak mereka. istilah "dengan rajin" dalam bahasa Ibrani berasal dari kata kerja yang berarti "mempertajam." Dalam contoh ini terkandung makna menembus secara dalam. Firman Tuhan tidak boleh diremehkan, melainkan harus menembus dan mempengaruhi seluruh bidang kehidupan manusia. Alkitab merupakan disiplin ilmu yang multigenerasi dan intergenerasi. Hal ini lebih dari sekedar tradisi kuno umat Israel mula-mula. ${ }^{11}$

Dengan demikian dapat dipahami bahwa Pendidikan Kristen yang berdasarkan Alkitab guna dapat mengajarkan setiap peserta didik tentang keselamatan yang ada di dalam Kristus. Supaya mereka mengetahui dan akhirnya menyadari serta hidup dalam keselamatan tersebut.

\section{Karena Alkitab dapat menyatakan kesalahan}

Kata dasar dari kata "kesalahan" adalah kata "salah." Di dalam Kamus Besar Bahasa Indonesia dijelaskan yang dimaksud dengan kata "salah" adalah tidak benar, tidak betul, keliru, khilaf, menyimpang dari yang seharusnya, luput, tidak mengenai sasaran, gagal, cela, cacat, kekeliruan. ${ }^{12}$ Sedangkan yang dimaksud dengan kata "kesalahan" ialah perihal salah, kekeliruan, kealpaan. ${ }^{13}$ Kata dasar dari kata "menyatakan" adalah kata "nyata." Arti kata "nyata" ialah terang (kelihatan, kedengaran, dsb), jelas sekali, kentara, benar-benar ada, ada buktinya, terbukti. ${ }^{14}$ Kata "menyatakan" berarti menerangkan, menjadikan nyata, menjelaskan, menunjukkan, memperlihatkan, menandakan, mengatakan, mengemukakan (pikiran, isi hati), melahirkan (isi hati, perasaan, dsb.), mempermaklumkan, membuktikan. ${ }^{15}$ Jadi yang dimaksud dengan kata "menyatakan kesalahan" ialah menjelaskan dan menunjukkan ketidakbenaran atau memperlihatkan atau membuktikan segala sesuatu yang menyimpang. Kata Yunani yang dipakai dalam kata "menyatakan kesalahan" ialah elegcov"elegchos" kata tersebut berbentuk kata benda berbentuk akusatif maskulin tunggal. Kata tersebut berasal dari

${ }^{11}$ Warren S. Benson dan Mark H. Senter III, Pedoman Lengkap Untuk Pelayanan Kaum Muda 2, Pent. Henry Lantang, (Bandung: Yayasan Kalam Hidup, 1999), hlm. 312.

${ }^{12}$ KBBI, hlm. 865.

${ }^{13} \mathrm{KBBI}$, hlm. 865.

${ }^{14}$ KBBI, hlm. 696.

${ }^{15}$ KBBI, hlm. 696. 
kata $\varepsilon^{\prime} \varepsilon \dot{\gamma} \gamma \chi \omega$ yang berarti teguran atau disiplin. ${ }^{16}$ Kata tersebut muncul dua kali dalam Perjanjian Baru yaitu : "bukti” muncul satu kali dan "menyatakan kesalahan" muncul satu kali.

Kesalahan yang dimaksud yaitu menyatakan dosa dan menolak ajaran sesat. Dosa mempunyai banyak segi. Paulus menggunakan macam-macam istilah untuk menjelaskan hal tersebut. Kata utama untuk dosa adalah hamartia "meleset dari sasaran" yang dipakai 64 kali oleh Paulus. Paulus sering memakai kata itu dalam bentuk tunggalnya. Dosa bukan hanya sekedar kejahatan yang dilakukan, melainkan suatu kekuatan yang membelnggu seseorang. Paulus memandang semua orang sebagai yang “terjual di bawah kuasa dosa (Rm. 7:14). Sebagaimana seorang budak dijual kepada seorang majikan, demikianlah semua orang masuk dalam kuasa dosa. Dosa pun bersifat universal baik orang Yahudi maupun orang non Yahudi (Rm. 3:23), dan pada hakikatnya semua orang harus dimurkai. ${ }^{17}$

Demikianlah Pendidikan Kristen diharapkan dapat menyadarkan peserta didik dari kehidupannya yang berdosa agar dapat memperbaiki dan kemudian hidup di dalam kebenaran Allah.

\section{Karena Alkitab memperbaiki kelakuan}

Kata dasar dari kata "kelakuan" adalah kata "laku." Di dalam Kamus Besar Bahasa Indonesia dijelaskan yang dimaksud dengan kata "laku” adalah perbuatan, gerak-gerik, tindakan, cara menjalankan atau berbuat. ${ }^{18}$ Sedangkan yang dimaksud dengan kata "kelakuan" ialah perbuatan, tingkah laku, perangai, perihal, keadaan. ${ }^{19}$ Kata dasar dari kata "memperbaiki" adalah kata "baik." Arti kata "baik" ialah elok, patut, teratur (apik, rapi, tidak ada celanya, dsb.), menguntungkan, berguna, manjur, tidak jahat (tentang kelakuan, budi pekerti, keturunan, dsb.), jujur, sembuh, pulih, selayaknya, sepatutnya. ${ }^{20}$ Kata "memperbaiki" berarti membetulkan (kesalahan, kerusakan, dsb.), menjadikan lebih baik (bagus, rapi, dsb). ${ }^{21}$ Jadi yang dimaksud dengan kata "memperbaiki kelakuan" ialah membetulkan tingkah laku dan perbuatan yang salah.

Kata Yunani yang dipakai dalam kata "memperbaiki kelakuan" ialah epanorywsiv atau epanorthosis yang berarti perbaikan dalam bidang kelakuan. Kata ini benda ini berbentuk akusatif feminim tunggal. Kata tersebut berasal dari kata óvo $\theta$ ó $\omega$ atau anorthoó yang berarti membuat lurus atau memulihkan. Kata anorthoó sendiri berasal dari kata depan óvóyang berarti kembali, oleh, melalui dan ó $\rho \theta$ ó yang artinya lurus atau tegak. ${ }^{22}$ Kata tersebut hanya muncul satu kali dalam Perjanjian Baru, yaitu hanya terdapat dalam ayat ini.

Yang dimaksud dengan kata "memperbaiki kelakuan" ialah memperbaiki apa yang salah pada tingkah laku manusia dengan kebenaran yang terdapat dalam Kitab Suci. Semua teori, teologi dan etika harus diuji dengan Alkitab. Bila ternyata bertentangan

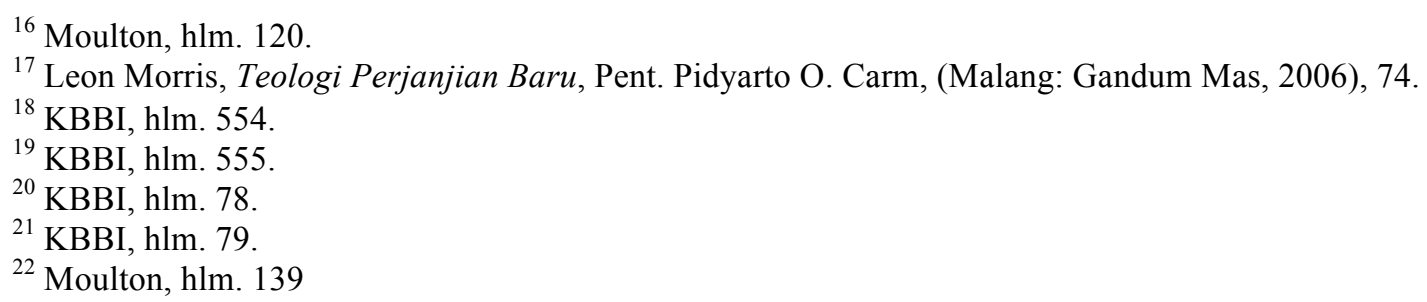


dengan pengajaran Alkitab, semua itu harus ditolak. Semua pengajaran harus diuji dan harus sejalan dengan pengajaran Yesus Kristus seperti dinyatakan dalam kitab suci. Itulah sebabnya betapa pentingnya Pendidikan Kristen didasarkan kepada Alkitab.

\section{Karena Alkitab dapat mendidik orang dalam kebenaran}

Kata "kebenaran" berasal dari kata dasar "benar" di dalam kamus besar bahasa Indonesia artinya ialah sesuai sebagaimana adanya (seharusnya), betul, tidak salah, tidak berat sebelah, adil, dapat dipercaya (cocok dengan keadaan yang sesungguhnya), tidak bohong, sah. ${ }^{23}$ Kata kebenaran sendiri dalam kamus besar bahasa Indonesia berarti keadaan (hal dan sebagainya) yang cocok dengan keadaan yang sesungguhnya, sesuatu yang sungguh-sungguh (benar-benar) ada, kelurusan hati, kejujuran. ${ }^{24}$ Sedangkan arti kata mendidik ialah memelihara dan memberi latihan (ajaran, tuntunan, pimpinan) mengenai akhlak dan kecerdasan pikiran.25 Mendidik orang dalam kebenaran dapat diartikan dengan memelihara atau memuridkan seseorang dalam hal yang sungguh-sungguh benar adanya. Sumber kebenaran ialah Alkitab.

Kata Yunani yang dipakai dalam kata "mendidik orang dalam kebenaran" ialah paideia en dikaiosunh atau paideia en dikaiosune. Akar kata dari kata paideia

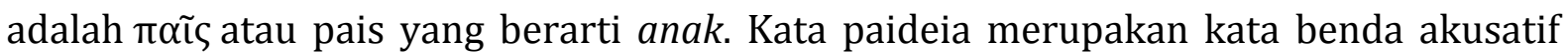
feminim tungal yang berarti disiplin atau didikan. ${ }^{26}$ Kata serupa dalam Perjanjian Baru muncul enam kali yaitu : didikan 1 kali, didiklah 1 kali, ganjaran 3 kali dan mendidik 1 kali. Kata dikaiosune merupakan kata benda datif feminim tunggal yang berarti kebenaran atau pembenaran. ${ }^{27}$ Kata serupa dalam Perjanjian Baru muncul sembilan puluh dua kali, yaitu: kebenaran 1 kali, baik 1 kali, dengan adil 2 kali, dibenarkan 2 kali, dibenarkan Allah 1 kali, hidup keagamaanmu 1 kali, keadilan 7 kali, keadilan-Nya 2 kali, benar 59 kali, kebenaran Allah 2 kali, kebenaran-Nya 1 kali, kebenaranmu 1 kali, kebenarannya 1 kali, kehendak Allah 1 kali, kewajiban agamamu 1 kali, membenarkan 1 kali, pembenaran 1 kali, soal kebenaran 1 kali.

Yang dimaksud dengan mendidik orang dalam kebenaran ialah mendidik seseorang supaya ia berjalan di atas jalan yang benar sesuai kehendak Allah. Manfaat dari mempelajari Kitab Suci dapat mendidik orang dalam kebenaran sehingga orang tersebut diperlengkapi untuk setiap perbuatan baik. mempelajari kitab suci bukanlah untuk diri sendiri, bukan hanya untuk kebaikan hati sendiri. Pertobatan yang membuat orang hanya berpikir untuk dirinya sendiri bahwa ia telah diselamatkan, bukanlah pertobatan yang benar. Orang tersebut harus mempelajari Kitab Suci agar dirinya berguna bagi Allah dan sesama manusia. Tidak seorangpun diselamatkan, kecuali agar dia menjadi suluh untuk menyelamatkan sesamanya. Yang pastinya, Pendidikan Kristen bertujuan supaya setiap manusia yang berdosa dapat melihat terang kasih Allah di dalam Kristus guna mengubah dan membenarkan hidup mereka.

\section{Kesimpulan}

\footnotetext{
${ }^{23} \mathrm{KBBI}$, hlm. 114

${ }^{24} \mathrm{KBBI}$, hlm. 114

${ }^{25} \mathrm{KBBI}$, hlm. 232.

${ }^{26}$ Moulton, hlm. 276.

${ }^{27}$ Moulton, hlm. 94.
} 
Dengan demikian dapat disimpulkan bahwa Urgensi Pendidikan Kristen berdasarkan Alkitab supaya Pendidikan Kristen menjadi sarana bagi setiap peserta didik untuk mengerti keselamatan di dalam Kristus dan mengenal-Nya bahkan menghidupi keselamatan itu dalam kehidupan praktisnya. Selain itu, supaya Pendidikan Kristen dapat menyadarkan peserta didik dari kehidupannya yang berdosa; dapat mengubah karakter setiap peserta didik agar senantiasa selaras dengan Alkitab serta senantiasa menuntun peserta didik untuk berjalan dalam kehendak Allah.

\section{Referensi}

Robert R. Boehlke, Sejarah Perkembangan Pikiran dan Praktek PAK, Jakarta: BPK Gunung Mulia, 2002.

Mavis L. Anderson, Pola mengajar Sekolah Minggu, Yayasan Kalam Hidup, Bandung, 1993.

E.G.Homrighausen, Pendidikan Agama Kristen, Jakarta: BPK Gunung Mulia, 1985.

Paulus Lilik Kristanto, Prinsip dan Praktek PAK Penuntun bagi Mahasiswa Teologi dan PAK, Pelayan Gereja, Guru Agama dan keluarga Kristen, Yogyakarta : Andi Offset.

Adi Putra, Misi Yesus Kepada Bangsa-bangsa Lain: Kajian Biblika terhadap Pelayanan Yesus di Galilea Berdasarkan Matius 4:12-17, Jakarta: Penerbit Vieka Wahana Semesta, 2015.

Haroul K. Moulton, Leksikon Analitis Bahasa Yunani Yang Direvisi, Pen. Robert Leland dan Stanley Pouw, (Jogjakarta : Randa's Family Press, 2009.

Warren S. Benson dan Mark H. Senter III, Pedoman Lengkap Untuk Pelayanan Kaum Muda 2, Pent. Henry Lantang, (Bandung: Yayasan Kalam Hidup, 1999), hlm. 312.

Leon Morris, Teologi Perjanjian Baru, Pent. Pidyarto O. Carm, (Malang: Gandum Mas, 2006.

Barnett, Paul. Jesus and the Rise of Early Christianity: A History New Testament Times. Illinois, USA: Intervarsity Press, 1999.

Bauer's, Walter. A Greek-English Lexicon of The New Testament And Other Early Christian Literature (BDAG) Third Edition. Chicago: The University of Chicago Press, 2000. Diedit oleh: Frederick William Danker. 